\title{
The clinical use of circulating tumor cells (CTCs) enumeration for staging of metastatic breast cancer (MBC): International expert consensus paper
}

Massimo Cristofanilli ${ }^{\mathrm{a}, *}$, Jean-Yves Pierga ${ }^{\mathrm{b}}$, James Reuben ${ }^{\mathrm{c}}$, Alfred Rademaker ${ }^{\mathrm{a}}$, Andrew A. Davis ${ }^{\mathrm{a}}$,

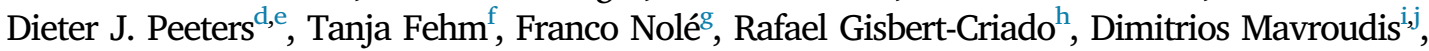
Salvatore Grisanti ${ }^{\mathrm{k}}$, Mario Giuliano, Jose A. Garcia-Saenz ${ }^{\mathrm{m}}$, Justin Stebbing ${ }^{\mathrm{n}}$, Carlos Caldas ${ }^{\circ}$, Paola Gazzaniga $^{\mathrm{p}}$, Luis Manso $^{\mathrm{q}}$, Rita Zamarchi ${ }^{\mathrm{r}}$, Angela Fernandez de Lascoiti ${ }^{\mathrm{s}}$, Leticia De Mattos-Arruda ${ }^{\mathrm{t}}$, Michail Ignatiadis $^{\mathrm{u}}$, Luc Cabel ${ }^{\mathrm{b}}$, Steven J. van Laere ${ }^{\mathrm{d}, \mathrm{e}}$, Franziska Meier-Stiegen ${ }^{\mathrm{f}}$, Maria-Teresa Sandri ${ }^{\mathrm{V}}$, Jose Vidal-Martinez $^{\mathrm{h}}$, Eleni Politaki ${ }^{\mathrm{i}, \mathrm{j}}$, Francesca Consoli ${ }^{\mathrm{k}}$, Daniele Generali ${ }^{\mathrm{w}}$, Maria Rosa Cappelletti ${ }^{\mathrm{w}}$, Eduardo Diaz-Rubio $^{\mathrm{m}}$, Jonathan Krell ${ }^{\mathrm{n}}$, Sarah-Jane Dawson ${ }^{\mathrm{x}, \mathrm{y}}$, Cristina Raimondi ${ }^{\mathrm{p}}$, Annemie Rutten ${ }^{\mathrm{d} \text {,e }}$, Wolfgang Janni ${ }^{\mathrm{Z}}$, Elisabetta Munzone ${ }^{\mathrm{g}}$, Vicente Carañana ${ }^{\mathrm{A}}$, Sofia Agelaki ${ }^{\mathrm{i}, \mathrm{j}}$, Camillo Almici ${ }^{\mathrm{k}}$, Luc Dirix ${ }^{\mathrm{d}, \mathrm{e}}$, Erich-Franz Solomayer ${ }^{\mathrm{B}}$, Laura Zorzino ${ }^{\mathrm{v}}$, Lauren Darrigues ${ }^{\mathrm{b}}$, Jorge S. Reis-Filho ${ }^{\mathrm{C}}$, Lorenzo Gerratana ${ }^{\mathrm{a}, \mathrm{D}}$, Stefan Michiels ${ }^{\mathrm{E}}$, François-Clément Bidard ${ }^{\mathrm{b}, 1}$, Klaus Pantel ${ }^{\mathrm{F}, 1}$

${ }^{a}$ Department of Medicine, Division of Hematology and Oncology, Robert H. Lurie Comprehensive Cancer Center, Feinberg School of Medicine, Northwestern University, Chicago, II, USA

${ }^{\mathrm{b}}$ Department of Medical Oncology, Institut Curie, PSL Research University, Paris, France

${ }^{\mathrm{c}}$ Department of Hematopathology, The University of Texas MD Anderson Cancer Center, Houston, TX, USA

${ }^{\mathrm{d}}$ Translational Cancer Research Unit, GZA Hospitals Sint-Augustinus, Antwerp, Belgium

e University of Antwerp, Antwerp, Belgium

${ }^{\mathrm{f}}$ Department of Gynecology and Obstetrics, Heinrich Heine University Düsseldorf, Düsseldorf, Germany

${ }^{g}$ Division of Medical Senology, European Institute of Oncology, Milan, Italy

${ }^{\mathrm{h}}$ Clinical Laboratory, Hospital Arnau de Vilanova, Valencia, Spain

${ }^{\mathrm{i}}$ Laboratory of Translational Oncology, School of Medicine, University of Crete, Heraklion, Greece

${ }^{\mathrm{j}}$ Department of Medical Oncology, University Hospital of Heraklion, Greece

${ }^{\mathrm{k}}$ Department of Transfusion Medicine, Laboratory for Stem Cells Manipulation and Cryopreservation, AO Spedali Civili di Brescia, Brescia, Italy

${ }^{1}$ Department of Clinical Medicine and Surgery, University Federico II, Naples, Italy

${ }^{\mathrm{m}}$ DCIBERONC, IdISCC Madrid, Spain

${ }^{\mathrm{n}}$ Division of Cancer, Department of Surgery and Cancer, Imperial College London, London, UK

${ }^{\circ}$ Cancer Research UK Cambridge Institute and Department of Oncology Li Ka Shing Centre, University of Cambridge, Cambridge, UK

${ }^{\mathrm{P}}$ Department of Molecular Medicine, Sapienza University of Rome, Rome, Italy

${ }^{\mathrm{q}}$ Hospital 12 de Octubre, Madrid, Spain

${ }^{\mathrm{r}}$ Veneto Institute of Oncology IOV-IRCCS, Padua, Italy

${ }^{\mathrm{s}}$ Hospital de Navarra, Pamplona, Spain

${ }^{\mathrm{t}}$ Val d'Hebron Institute of Oncology, Val d'Hebron University Hospital, and Universitat Autònoma de Barcelona, Barcelona, Spain

${ }^{\mathrm{u}}$ Department of Medical Oncology and Breast Cancer Translational Research Laboratory, Institut Jules Bordet, Université Libre de Bruxelles, Brussels, Belgium

${ }^{v}$ Division of Laboratory Medicine, Humanitas Reseach Hospital, Rozzano, Milan, Italy

${ }^{\mathrm{w}}$ Women Cancer Center, Azienda Socio Sanitaria Territoriale di Cremona, University of Trieste, Italy

${ }^{\mathrm{x}}$ Peter MacCallum Cancer Centre, East Melbourne, Victoria, Australia

${ }^{y}$ Sir Peter MacCallum Department of Oncology, The University of Melbourne, Victoria, Australia

${ }^{\mathrm{z}}$ Frauenklinik, University of Ulm, Ulm, Germany

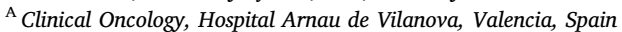

${ }^{\mathrm{B}}$ Saarland University, Homburg, Germany

${ }^{\mathrm{C}}$ Department of Pathology, Memorial Sloan-Kettering Cancer Center, New York, NY, USA

${ }^{D}$ Department of Medicine, University of Udine, Udine, UD, Italy

${ }^{\mathrm{E}}$ Service de Biostatistique et d'Epidémiologie, Gustave Roussy, CESP, INSERM U1018, University Paris-Saclay, University Paris-Sud, Villejuif, France

${ }^{\mathrm{F}}$ Department of Tumor Biology, Center of Experimental Medicine, University Cancer Center Hamburg, University Medical Center Hamburg-Eppendorf, Hamburg, Germany

* Corresponding author at: FACP, Robert H Lurie Comprehensive Cancer Center, Northwestern University, 710 N Fairbanks Court, Suite 8-250A, Chicago, IL, 60611, USA.

E-mail address: Massimo.Cristofanilli@nm.org (M. Cristofanilli).

${ }^{1} \mathrm{~F}-\mathrm{CB}$ and $\mathrm{KP}$ are co-senior authors. 


\section{A R T I C L E I N F O}

\section{Keywords:}

Circulating tumor cells

CTCs

Metastatic breast cancer

MBC

Biomarker

Survival

\begin{abstract}
A B S T R A C T
Background: The heterogeneity of metastatic breast cancer (MBC) necessitates novel biomarkers allowing stratification of patients for treatment selection and drug development. We propose to use the prognostic utility of circulating tumor cells (CTCs) for stratification of patients with stage IV disease.

Methods: In a retrospective, pooled analysis of individual patient data from 18 cohorts, including 2436 MBC patients, a CTC threshold of 5 cells per $7.5 \mathrm{ml}$ was used for stratification based on molecular subtypes, disease location, and prior treatments. Patients with $\geq 5$ CTCs were classified as Stage IV $_{\text {aggressive, }}$, those with $<5$ CTCs

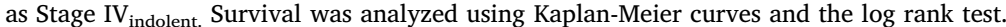

Results: For all patients, Stage $\mathrm{IV}_{\text {indolent }}$ patients had longer median overall survival than those with Stage $\mathrm{IV}_{\text {aggressive }}(36.3$ months vs. 16.0 months, $\mathrm{P}<0.0001)$ and similarly for de novo MBC patients (41.4 months Stage $\mathrm{IV}_{\text {indolent }}$ Vs. 18.7 months Stage $\mathrm{IV}_{\text {aggressive, }} \mathrm{p}<0.0001$ ). Moreover, patients with Stage $\mathrm{IV}_{\text {indolent }}$ disease had significantly longer overall survival across all disease subtypes compared to the aggressive cohort: hormone receptor-positive (44 months vs. 17.3 months, $\mathrm{P}<0.0001$ ), HER2-positive ( 36.7 months vs. 20.4 months, $\mathrm{P}<0.0001)$, and triple negative $(23.8$ months vs. 9.0 months, $\mathrm{P}<0.0001)$. Similar results were obtained regardless of prior treatment or disease location.

Conclusions: We confirm the identification of two subgroups of MBC, Stage $\mathrm{IV}_{\text {indolent }}$ and Stage $\mathrm{IV}_{\text {aggressive }}$, independent of clinical and molecular variables. Thus, CTC count should be considered an important tool for staging of advanced disease and for disease stratification in prospective clinical trials.
\end{abstract}

\section{Introduction}

Metastatic breast cancer (MBC) can occur with de novo presentation or upon the development of recurrent disease after completion of primary (local) treatment (Weigelt et al., 2005). Once diagnosed by physical exam, radiological tests, and pathology, current treatment of this condition is palliative. In spite of the increasing availability of targeted and systemic therapies, approximately 41,000 women in the United States and over half a million worldwide die of MBC annually (Siegel et al., 2018; Ghoncheh et al., 2016). In order to better assess survival benefit from novel potential treatments in prospective, randomized clinical trials, there is a critical need of new tools for prognostic stratification, particularly with regards to endocrine therapies (Koren and Bentires-Alj, 2015; Polyak, 2011).

The detection of circulating tumor cells (CTCs) is prognostic during the course of the disease in women with MBC (Cristofanilli et al., 2004). Several prospective studies, including a large pooled analysis, confirmed the prognostic value of baseline CTC detection in both first-line and refractory MBC (Bidard et al., 2014; Cristofanilli et al., 2005). The prognostic value of CTC detection and enumeration stimulated a number of molecular studies aimed at evaluating the biological features of CTCs. These studies demonstrated the fundamental role of these cells in the metastatic process and suggested potential therapeutic approaches (Yu et al., 2013; Powell et al., 2012; Meng et al., 2006; Yu et al., 2014). A single, prospective, randomized study was designed to evaluate the clinical utility of CTC enumeration by testing the hypothesis that an early change of chemotherapy regimen could modify outcome of patients with a baseline level of $\geq 5$ CTCs per $7.5 \mathrm{~mL}$ of blood (Smerage et al., 2014). This study failed to demonstrate the validity of this therapeutic approach, but it confirmed that patients with elevated CTC count at baseline had worse outcomes not affected by current standard therapies when compared to patients with $<5$ CTCs (Smerage et al., 2014).

The American Joint Committee on Cancer (AJCC) TNM staging classification provides an assessment of disease burden based on anatomical location and disease characteristics to define prognosis (Giuliano et al., 2017). In the last revisions of the staging system, the use of novel diagnostic tests has been included (Giuliano et al., 2017). Nevertheless, Stage IV breast cancer, or MBC, continues to be considered a uniform disease in spite of known variability in clinical outcomes in patients with different disease subtypes and sites of metastasis. We postulated that CTC enumeration could be used to stratify patients with $\mathrm{MBC}$, irrespective of disease subtype, line of therapy, and site of disease. Here, by retrospective analysis of individual patient data from 18 cohorts, including 2436 patients with MBC, we demonstrated that
CTC enumeration should be used to evaluate prognosis and expect that CTC-based staging will impact the development for new treatments of MBC.

\section{Methods}

We performed a large, retrospective pooled analysis of individual patient data to demonstrate that CTC enumeration could effectively stratify MBC into two distinct subgroups, indolent (Stage $\mathrm{IV}_{\text {indolent }}$ ) and

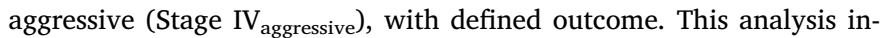
cluded patients from the 17 European Centers participating in the European Pooled Analysis Consortium (EPAC) and a single large U.S. institution, the MD Anderson Cancer Center (MDACC) (Bidard et al., 2014). Centers are listed in Supplemental Table 1. The anonymized data were transferred to the Robert $\mathrm{H}$. Lurie Comprehensive Cancer Center-Bioinformatics Core Facility. A retrospective Institutional Review Board-approved protocol was used to access and analyze the data. For all participants, CTC enumeration was performed using the CellSearch $^{\mathrm{TM}}$ method (Menarini Silicon Biosystems, LLC), which is approved by the Food and Drug Administration (FDA), to evaluate whole blood specimens collected before initiation of a new treatment.

Estrogen receptor, progesterone receptor, and HER2 status were performed at each participating institution following standard procedures and guidelines, and patients were treated with endocrine therapy, chemotherapy, HER2-targeted therapy, or a combination as appropriate. Standard imaging studies were used for baseline staging and response assessment. Disease in patients with fewer than 5 CTCs per $7.5 \mathrm{~mL}$ of blood was classified as Stage $\mathrm{IV}_{\text {indolent }}$. Disease in those with 5 or more CTCs per $7.5 \mathrm{~mL}$ of blood was classified as Stage IV $_{\text {aggressive. }}$ The study diagram is shown in Supplemental Fig. 1.

\subsection{Statistical analysis}

Patient characteristics were summarized through descriptive analysis and differences between datasets were tested through Pearson's chi-square test. Continuous variables were reported through median and range, whereas categorical variables were described through frequency distribution.

Survival analyses were performed in each cohort separately, and then the cohorts were combined. Overall survival was defined as the time from baseline CTC enumeration to death from any cause or date of last follow-up. Progression-free survival was defined as the time from baseline CTC enumeration to disease progression (according to RECIST criteria) or death from any cause or date of last follow-up. Censoring was applied to patients without an endpoint event at the last follow-up 
visit. Hazard ratios (HR) and confidence intervals (CI) were reported. A $P$ value of less than 0.05 was considered to indicate statistical significance. Survival was analyzed by log-rank test and represented by Kaplan-Meier estimator plot. Cumulative Hazard function was represented through Nelson-Aalen estimator. Patient subgroups were compared using multivariate analyses based on the Cox proportionalhazards method. HR and their P-values were calculated using Cox regression. Statistical analysis was performed using SAS software, Version 9.4 (SAS Institute Inc. (2014) Cary, NC) and STATA, Version 14.2 (StataCorp LP. (2015) College Station, TX).

\section{Results}

\subsection{Individual analysis}

The EPAC cohort consisted of individual patient data of MBC patients with baseline CTCs collected prior to initiation of a new treatment. Data were collected from 17 centers in Europe from 2003 to 2012. The EPAC cohort included 1944 patients. The details for how this cohort was obtained were published previously (Bidard et al., 2014). A CTC cutoff of 5 CTCs per $7.5 \mathrm{~mL}$ was selected based on prior studies (Cristofanilli et al., 2004). A total of 1033 (53.1\%) patients had Stage $\mathrm{IV}_{\text {indolent }}$ disease, defined as $<5$ CTCs per $7.5 \mathrm{~mL}$ of blood, and 911 patients $(46.9 \%)$ had baseline CTCs of $\geq 5$ (Stage $\mathrm{IV}_{\text {aggressive }}$ disease). Median CTC count was 3 per $7.5 \mathrm{~mL}$ (range $0-58,160$ ). The second cohort consisted of individual patient data from 492 patients treated at the MDACC from 2002 to 2009. The MDACC cohort had a total of 303 (61.6\%) patients with Stage $\mathrm{IV}_{\text {indolent }}$ disease and 189 patients $(38.4 \%)$ with Stage $\mathrm{IV}_{\text {aggressive }}$ disease. Median CTC count was 2 per $7.5 \mathrm{~mL}$ (range 0-1,780).

First, each cohort was analyzed individually using Cox regression analyses. In the EPAC cohort, the Stage $\mathrm{IV}_{\text {aggressive }}$ group had significantly shorter progression-free survival (HR 1.91, 95\% CI $1.72-2.12,12.4$ months vs. 23.6 months, $\mathrm{p}<0.0001$ ) and OS (HR $2.68,95 \%$ CI $2.35-3.06,15.4$ months vs. 37.1 months, $\mathrm{P}<0.0001$ ), compared with the Stage $\mathrm{IV}_{\text {indolent }}$ group. Similarly, in the MDACC cohort, the Stage $\mathrm{IV}_{\text {aggressive }}$ group was associated with significantly shorter progression-free survival (HR 1.50, 95\% CI 1.24-1.82, 5.94 months vs. 6.64 months, $\mathrm{P}<0.007$ ) and overall survival (HR 2.43, $95 \%$ CI $1.45-2.29,19.1$ months vs. 31.3 months, $\mathrm{P}<0.0001)$ compared with the Stage $I_{\text {indolent }}$ group (Supplemental Fig. 2).

\subsection{Combined analysis}

Data from 2436 patients were included in the combined analysis including 533 patients with de novo stage IV disease (Table 1). The median age for the combined cohort was 57 years (range 27-91), and the median follow-up was 14.9 months (0.1-90.1). At the time of last follow-up, 1878 patients (77\%) had progressed and 1221 (50\%) had died of MBC. Seventy-four percent (1755 patients) were estrogen receptor positive, $24 \%$ (571 patients) were HER2 positive, and 15\% (358 patients) had triple-negative breast cancer.

At baseline, approximately $46 \%$ of patients had not received systemic therapy in the advanced setting including 533 patients with de novo disease. Approximately $20 \%$ of patients had been treated with one prior line of therapy, and $34 \%$ of patients had been treated with two or more lines of therapy at the time of baseline CTC collection. In terms of sites of metastasis, $68 \%$ had visceral metastasis, $66 \%$ had bone metastasis, and $43 \%$ had both visceral and bone metastases. After CTC collection, approximately $44 \%$ of patients were treated with chemotherapy, $37 \%$ received chemotherapy combined with a biologic or targeted therapy, $13 \%$ had endocrine monotherapy, and the remaining $6 \%$ were classified as other.

There was a statistically significant difference in OS (36.3 months vs. 16.0 months, $\mathrm{P}<0.0001$, log-rank) in favor of patients with Stage $\mathrm{IV}_{\text {indolent }}$ disease, compared to those with Stage $\mathrm{IV}_{\text {aggressive }}$ disease (Fig. 1A). Moreover, CTC enumeration was also able to stratify patients with de novo Stage IV disease. Median OS of patients with de novo Stage $\mathrm{IV}_{\text {indolent }}$ disease compared to that of the de novo Stage $\mathrm{IV}_{\text {aggressive }} \mathrm{pa}$ tients was 41.4 months versus 18.7 months $(\mathrm{P}<0.0001$, log-rank) (Fig. 1B). The indolent cohort had better OS irrespective of the location of disease. Stage $\mathrm{IV}_{\text {indolent }}$ patients with visceral disease had a median overall survival of 29.9 months compared to 13.2 months for the Stage $\mathrm{IV}_{\text {aggressive }}$ group ( $\mathrm{p}<0.0001$ by log rank test) (Fig. 1C). Similarly, the median OS in patients with bone-only disease was 46.9 months compared to 23.8 months ( $p<0.0001$ by log rank test) (Fig. 1D), confirming the significant prognostic difference between the two stage IV subgroups defined by CTC frequency.

\subsection{CTCs, lines of therapy, and disease subtype}

Patients with MBC are treated with a sequence of systemic therapies selected following evaluation of standard biomarkers, such as hormone receptors and HER-2 status. Endocrine therapy is the standard of care for patients with hormone receptor-positive disease, HER2-targeted biological therapies are used primarily in combination with chemotherapy. Triple-negative breast cancer patients are primarily treated with cytotoxic chemotherapy, frequently combinations regimens. The probability of response and the ability to control disease progression decreases when patients receive multiple lines of treatment. Patients that failed first-line therapy had CTCs positivity that varies in disease subtypes, approximately $52 \%$ in hormone-receptor positive disease and

Table 1

Demographics and clinical characteristics of the patients at baseline for individual cohorts and combined cohort.

\begin{tabular}{|c|c|c|c|c|c|}
\hline Patient Characteristic & & \multicolumn{3}{|l|}{ Cohort } & $\mathrm{P}$ value \\
\hline Age & Median [Range] (Years) & 60 [23-91] & $53[23-82]$ & 57 [23-91] & $<0.0001$ \\
\hline Died & & $929 / 1944(47.8 \%)$ & $292 / 492(59.4 \%)$ & $1221 / 2436(50.1 \%)$ & $<0.0001$ \\
\hline \multirow{2}{*}{ Lines of MBC Treatment } & Untreated & 792/1713 (46.2\%) & $220 / 490(44.9 \%)$ & $1012 / 2203(45.9 \%)$ & 0.61 \\
\hline & $\geq 1$ Prior Treatments & 921/1713 (53.8\%) & $270 / 490(55.1 \%)$ & $1191 / 2203(54.1 \%)$ & \\
\hline Molecular Subtype & $\mathrm{HR}+$ & $1166 / 1880[62.0 \%]$ & $274 / 489[56.0 \%]$ & $1440 / 2369[60.8 \%]$ & 0.016 \\
\hline \multirow[t]{2}{*}{ Site of Metastasis } & Visceral & $1318 / 1897(69.5 \%)$ & $306 / 492(62.2 \%)$ & $1624 / 2389(68.0 \%)$ & 0.002 \\
\hline & Bone & $1240 / 1897(65.4 \%)$ & $326 / 492(66.3 \%)$ & $1566 / 2389(65.6 \%)$ & 0.71 \\
\hline \multirow[t]{2}{*}{ CTC Count } & $<5$ & 1033/1944 (53.1\%) & $304 / 492(61.8 \%)$ & $1337 / 2436(54.9 \%)$ & $<0.001$ \\
\hline & $\geq 5$ & $911 / 1944(46.9 \%)$ & $188 / 492(38.2 \%)$ & $1099 / 2436(45.1 \%)$ & \\
\hline
\end{tabular}

MBC: metastatic breast cancer, EPAC: European Pooled Analysis Consortium, MDACC: MD Anderson Cancer Center, HR +: hormone-receptor positive, TNBC: triplenegative breast cancer, HER-2: human epidermal growth factor receptor 2. 
A

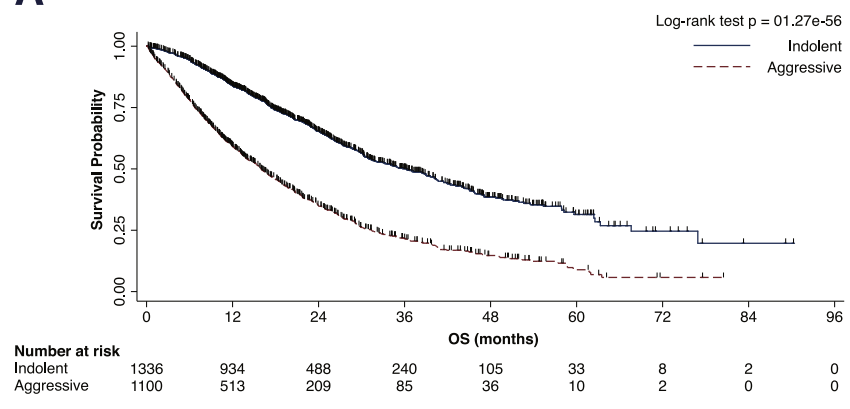

C

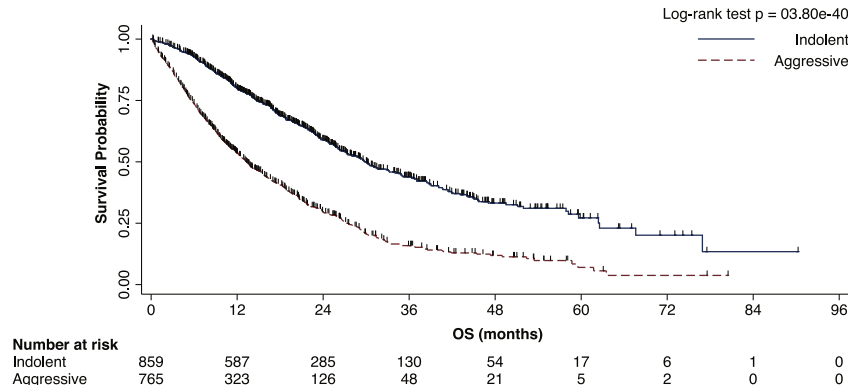

E

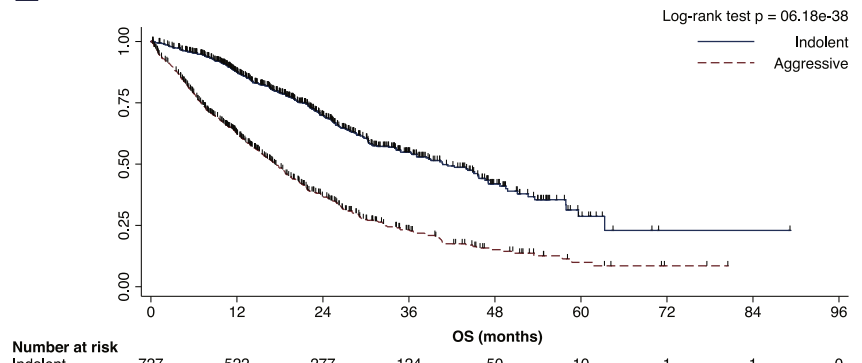

B

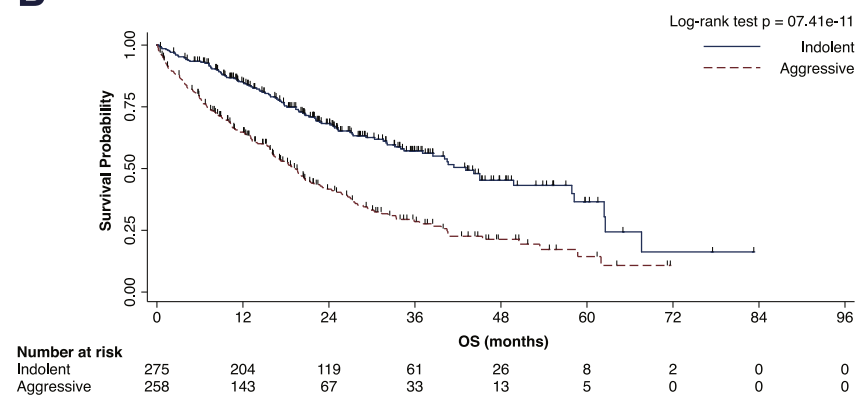

D

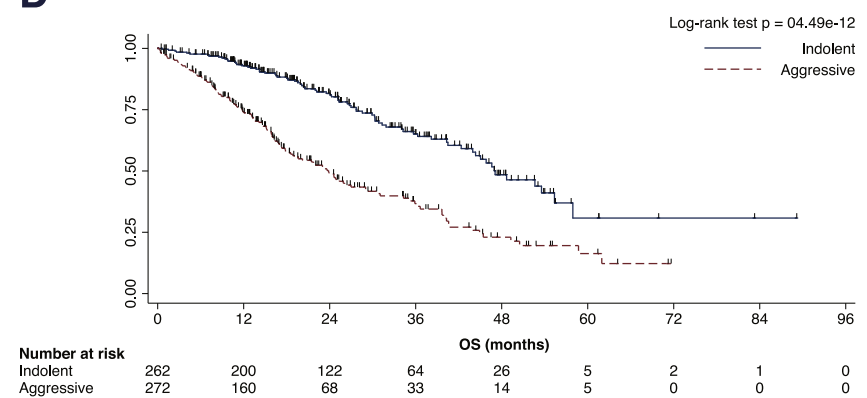

$\mathbf{F}$

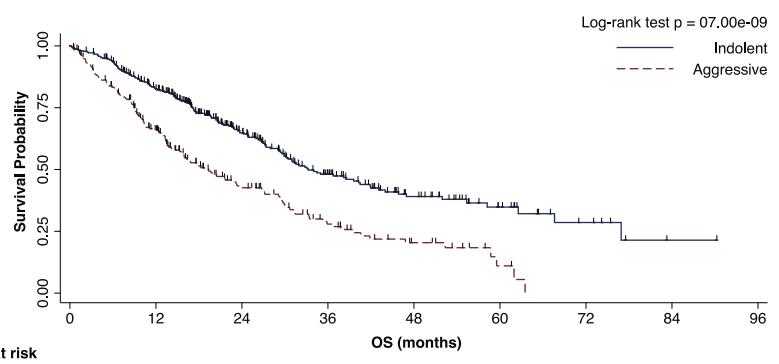

$\begin{array}{llllllllll}\begin{array}{l}\text { Number at risk } \\ \text { Indolent t }\end{array} & 357 & 270 & 143 & 78 & 41 & 18 & 7 & 1 & 0 \\ \text { Aggressive } & 214 & 118 & 55 & 27 & 12 & 3 & 0 & 0 & 0\end{array}$

G

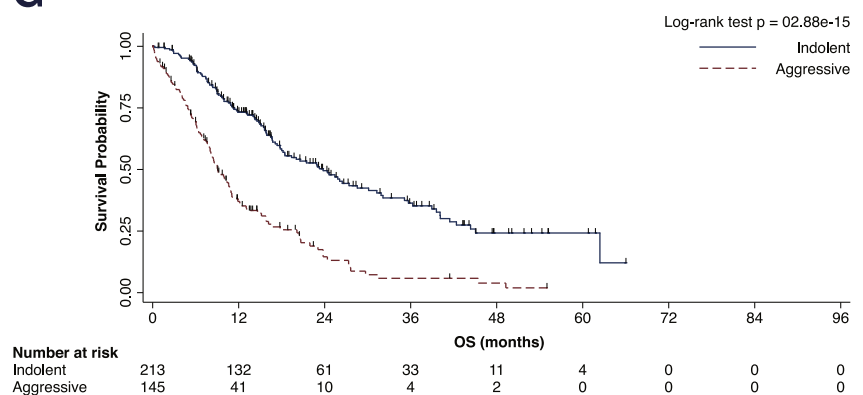

Fig. 1. Overall survival for Stage $I_{\text {indolent }}$ versus Stage $\mathbf{I V}_{\text {aggressive }}$ patients. Kaplan-Meier estimate of the duration of overall survival of patients stratified as Stage $I_{\text {indolent }}$ (blue) and Stage $I_{\text {aggressive }}($ red) for A) the entire cohort, B) patients with de novo disease, C) patients with visceral metastases, D) patients with bone only metastases, E) and those with hormone-receptor positive, F) HER-2 positive, and G) triple-negative breast cancer. Censored data are indicated by tick marks. (For interpretation of the references to colour in this figure legend, the reader is referred to the web version of this article).

$33 \%$ and $37 \%$ respectively for HER2 positive and triple negative breast cancers. Analysis of the combined cohort demonstrated that patients with untreated recurrent Stage $\mathrm{IV}_{\text {indolent }}$ had a median $\mathrm{OS}$ of 44.6 months compared to only 22.8 months in patients with Stage $\mathrm{IV}_{\text {aggressive }}$ disease ( $\mathrm{p}<0.0001$, log-rank) (Supplemental Fig. 3). In patients with refractory disease who had received more than one line of systemic therapy, CTCs discriminated the two prognostic groups (27.3 months vs. 12.0 months, respectively, $\mathrm{p}<0.0001$, log-rank).

The combined cohort was then stratified based on disease subtypes. The Stage $I_{\text {indolent }}$ cohort had significantly longer overall survival across all disease subtypes compared to the aggressive cohort. Specifically, for patients with hormone receptor-positive disease, overall survival was significantly longer for patients with Stage $\mathrm{IV}_{\text {indolent }}$ compared to Stage $\mathrm{IV}_{\text {aggressive }}$ disease (40.7 months vs. 17.3 
months, $\mathrm{P}<0.0001$, log-rank). Stage $\mathrm{IV}_{\text {indolent }}$ also had longer overall survival for triple-negative breast cancer (23.8 months vs. 9.1 months, $\mathrm{P}<0.0001$, log-rank) and HER2-positive subgroups (33.2 months vs. 19.4 months, $\mathrm{P}<0.0001$, log-rank) (Fig. 1E-G). Cumulative hazard ratio for Stage $I V_{\text {indolent }}$ and Stage $I V_{\text {aggressive }}$ classification by breast cancer subtype distinguished a particularly aggressive triple-negative breast cancer cohort (Fig. 2A and B).

CTC enumeration was also able to stratify survival for both untreated patients and patients with prior lines of treatment, across subtypes for Stage $\mathrm{IV}_{\text {indolent }}$ versus Stage $\mathrm{IV}_{\text {aggressive }}$ with hormone receptorpositive (untreated: 51.1 months vs. 26.4 months, $\mathrm{P}<0.0001$; prior treatment: 30.2 months vs. 12.8 months, $\mathrm{P}<0.0001$, log-rank), triple negative (untreated: 36.3 months vs. 9.1 months, $\mathrm{P}<0.0001$; prior treatment: 15.9 months vs. 9.0 months, $\mathrm{P}<0.0001$, log-rank), and HER2-positive disease (untreated: 55.4 months vs. 29.7 months, $\mathrm{P}<0.0001$; prior treatment: 29.2 months vs. 13.3 months, $P<0.0001$, log-rank) (Supplemental Fig. 4). In the refractory setting, the Stage $I_{\text {indolent }}$ group performed consistently better within each disease subtype compared to the Stage $\mathrm{IV}_{\text {aggressive }}$ group. For the total cohort, a significant survival difference between Stage $\mathrm{IV}_{\text {indolent }}$ and Stage $I_{\text {aggressive }}$ was identified across all analyzed subgroups (Fig. 3). In multivariate analysis, prior treatment, grade 3 tumors, triple-negative breast cancer, visceral metastasis, and CTC count $\geq 5$ were associated with significantly worse survival (Table 2). Of all covariates included in the analysis, Stage $\mathrm{IV}_{\text {aggressive }}$ disease based on CTC count was the most significant predictor (HR 2.71, 95\% CI 2.35-3.12, P < 0.0001).

\section{Discussion}

The recent improved breast cancer outcomes are primarily related to the diagnosis of disease at an early, regional stage followed by the application of multidisciplinary care including surgery, systemic therapy, and radiotherapy (DeSantis et al., 2017). Our current understanding of disease biology has enabled sophisticated and biologically driven disease stratification and staging and introduced personalized treatment selection that has also impacted survival and quality of life (Siegel et al., 2018). MBC continues to be considered incurable, however, and is treated with palliative intent in spite of increased availability of FDA-approved therapeutic drugs designed to treat specific disease subtypes such as hormone receptor-positive disease (Gradishar et al., 2018). There is a critical need to better characterize MBC heterogeneity and to apply validated biomarkers for disease stratification and personalized, cost-effective treatment selection (Van Poznak et al., 2015; Duffy et al., 2017). Here, we demonstrate the validity of

A

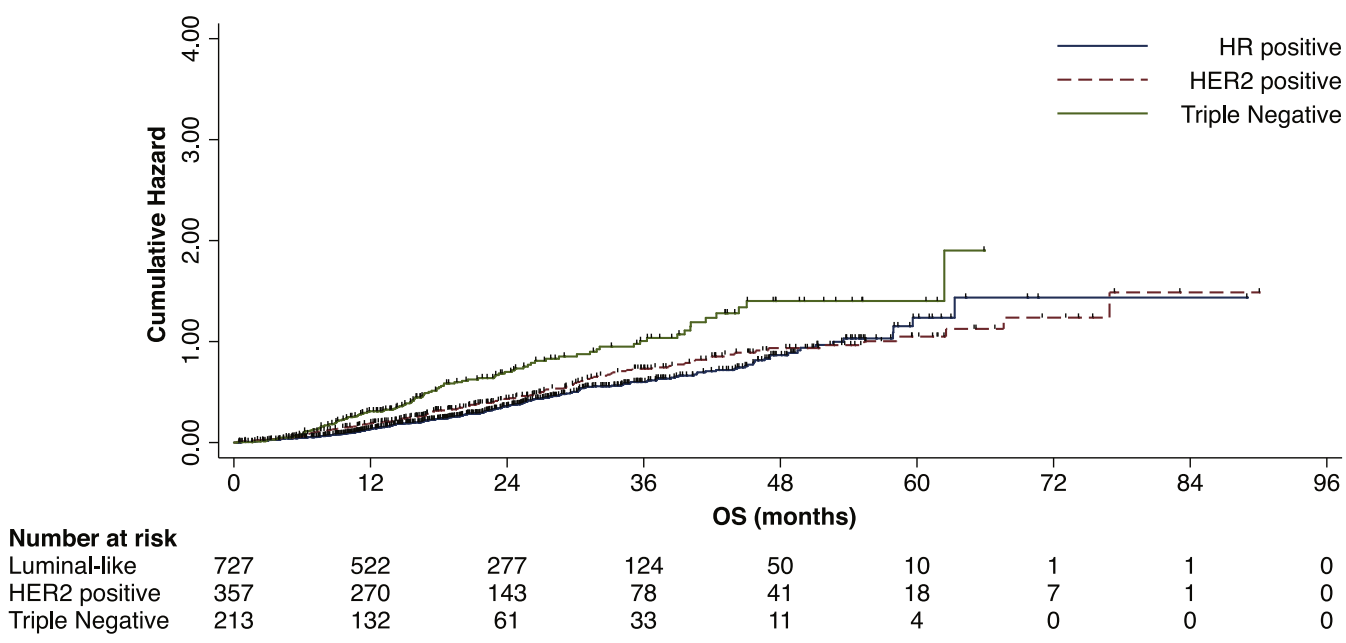

B

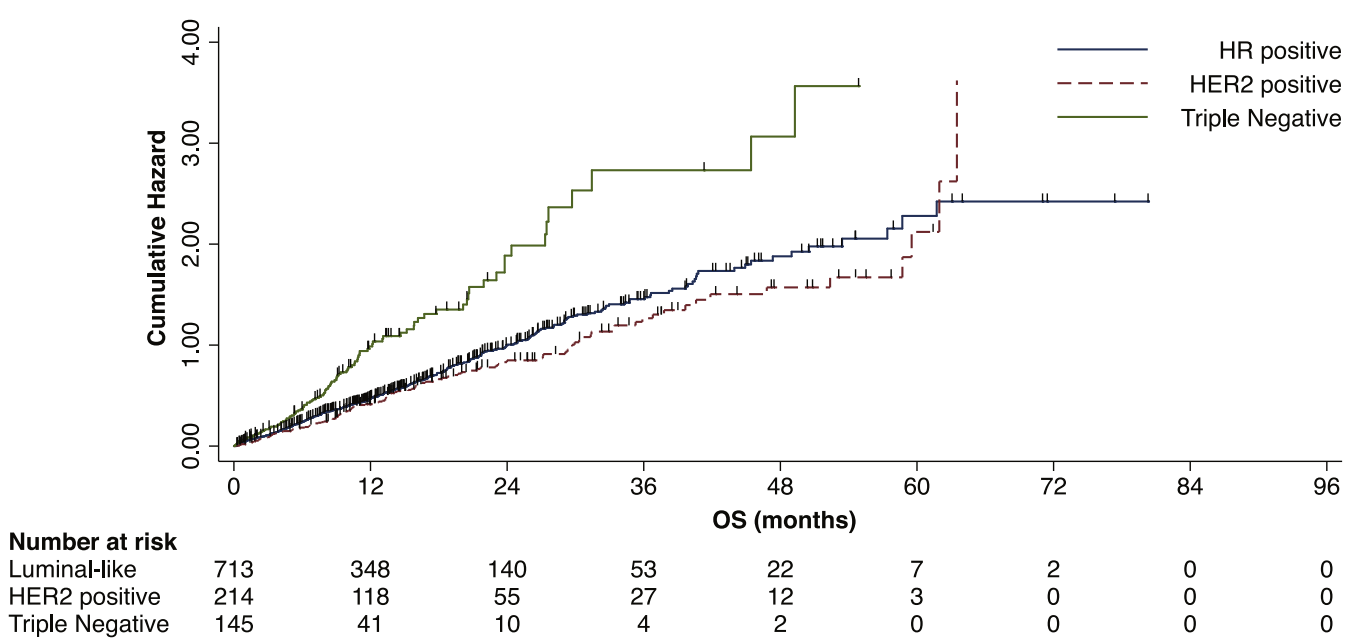

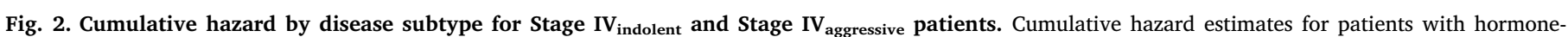
receptor positive, HER-2 positive, and triple-negative breast cancer for those with A) Stage IV $_{\text {indolent }}$ disease and B) Stage IV $_{\text {aggressive }}$ disease Censored data are indicated by tick marks. 


\section{Age at baseline}

$<45$

$\geq 45$ and $\leq 65$

\section{Grade}

2

\section{Subtype}

HR positive

Triple Negative

Site of Metastasis

Bone only

Visceral

Line of treatment

First line

1012

Beyond the first line

1191

Type of metastatic onset

Relapsed

De novo

Overall
HR $(95 \% \mathrm{Cl})$

$0.50(0.38,0.66)$

$0.43(0.37,0.51)$

$0.34(0.28,0.41)$

$0.41(0.23,0.71)$

$0.37(0.30,0.45)$

$0.40(0.33,0.47)$

$0.37(0.32,0.44)$

$0.51(0.40,0.64)$

$0.35(0.27,0.46)$

$0.39(0.29,0.52)$

$0.42(0.37,0.48)$

$0.40(0.33,0.49)$

$0.42(0.36,0.49)$

$0.39(0.34,0.45)$

$0.45(0.35,0.58)$

$0.41(0.37,0.46)$

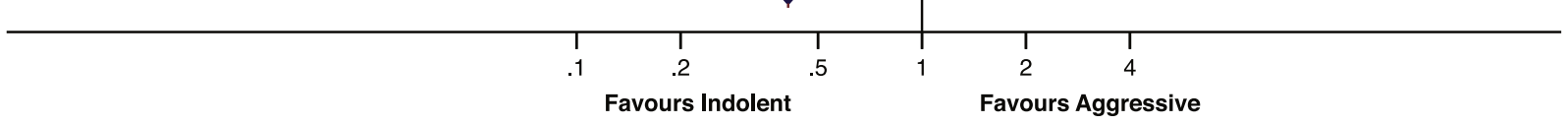

Fig. 3. Forest plot of overall survival, according to subgroups. HR denotes hazard ratio, and CI denotes confidence interval.

Table 2

Multivariate cox regression for overall survival.

\begin{tabular}{|c|c|c|c|c|c|}
\hline \multicolumn{2}{|c|}{ Patient Characteristic } & \multirow{2}{*}{$\frac{\mathrm{HR}}{1}$} & \multicolumn{2}{|c|}{$95 \% \mathrm{CI}$} & \multirow[t]{2}{*}{$P$ value } \\
\hline Age & $<45$ & & & & \\
\hline & $\geq 45$ and $\leq 65$ & 1.02 & 0.84 & 1.24 & 0.852 \\
\hline & $\geq 65$ & 1.18 & 0.96 & 1.45 & 0.118 \\
\hline Lines of MBC & Untreated & 1 & & & \\
\hline Treatment & $\begin{array}{l}\geq 1 \text { Prior } \\
\text { Treatments }\end{array}$ & 2.03 & 1.75 & 2.35 & $<0.0001$ \\
\hline \multirow[t]{3}{*}{ Grade } & 1 & 1 & & & \\
\hline & 2 & 1.14 & 0.83 & 1.57 & 0.413 \\
\hline & 3 & 1.46 & 1.06 & 2.00 & 0.02 \\
\hline \multirow[t]{3}{*}{ Molecular Subtype } & HR positive & 1 & & & \\
\hline & HER2 positive & 0.89 & 0.74 & 1.01 & 0.176 \\
\hline & TNBC & 1.90 & 1.57 & 2.31 & $<0.0001$ \\
\hline \multirow[t]{2}{*}{ Site of Metastasis } & Bone only & 1 & & & \\
\hline & Visceral & 1.86 & 1.56 & 2.20 & $<0.0001$ \\
\hline \multirow{2}{*}{$\begin{array}{l}\text { Type of metastatic } \\
\text { onset }\end{array}$} & Relapsed & 1 & & & \\
\hline & De novo & 0.92 & 0.78 & 1.09 & 0.351 \\
\hline \multirow[t]{2}{*}{ CTC Count } & $<5$ & 1 & & & \\
\hline & $\geq 5$ & 2.71 & 2.35 & 3.12 & $<0.0001$ \\
\hline
\end{tabular}

MBC: metastatic breast cancer, HR: hazard ratio, CI: confidence interval. incorporating CTC enumeration for a new classification of MBC.

As a strong prognostic biomarker in MBC, CTCs are ideal for disease stratification. In this study, including the largest dataset ever reported across 18 international centers, we tested the hypothesis that CTC count could be used to identify two cohorts with distinctly different outcomes, Stage $\mathrm{IV}_{\text {indolent }}$ and Stage $\mathrm{IV}_{\text {aggressive }}$. We demonstrated that patients with the former classification had statistically significant longer survival compared to the Stage $\mathrm{IV}_{\text {aggressive }}$ group in all the disease categories analyzed, including a cohort of patients with de-novo advanced disease at initial diagnosis. The CTC-based stratification demonstrated significant differences in overall survival across hormone-receptor positive, HER2-positive, and triple-negative breast cancer both for untreated patients and patients with prior treatment. Moreover, patients with visceral or bone only metastasis were also stratified accordingly. In multivariate analysis, CTC count was the strongest prognostic biomarker for patient survival. Thus, CTC count should be used to better classify the clinical and molecular heterogeneity of patients with MBC.

In the last decade, several novel agents were approved by the Federal Drug Administration (FDA) and European Medical Agency (EMA) for the management of MBC with the predominance of drugs 
indicated for hormone receptor-positive MBC. Clinical trials have focused on inclusion of patients with clinically defined "endocrine-sensitive" or "endocrine-resistant" disease with some differences in the criteria used for the definition, making cross-study comparisons difficult (Finn et al., 2015, 2016; Turner et al., 2015; Baselga et al., 2012; Sledge et al., 2017; Hortobagyi et al., 2016). In particular, two studies with appropriate long-term follow-up, PALOMA-1 and BOLERO-2, failed to demonstrate an improvement in overall survival of patients treated with hormone pathway-targeted agents in spite of a statistically significant impact on progression-free survival, raising questions about the application of a combination strategy for all patients with advanced disease (Finn et al., 2017; Piccart et al., 2014). We hypothesized that in these studies, the significant benefit of the investigational agents demonstrated with improved response and prolonged progression-free survival did not translate into an overall survival advantage because, irrespective of randomization, enrolled patients of both stages of the disease (indolent and aggressive) potentially impacted the final outcome. In fact, the aim of randomization in clinical trial design is to properly stratify patients into two or more groups in order to limit biases and to demonstrate a difference between pre-specified interventions. The findings in this study suggest that current clinical and molecular variables are insufficient to adequately stratify patients in order to demonstrate survival impact as the primary outcome. Patients with Stage $\mathrm{IV}_{\text {aggressive }} \mathrm{MBC}$ may receive greater relative benefit from novel therapies compared to Stage $\mathrm{IV}_{\text {indolent }}$. However, Stage $\mathrm{IV}_{\text {aggressive }}$ disease constitutes only approximately $40 \%$ of cases, and survival benefits in these patients may be diluted over time by the lack of significant therapeutic value in the larger cohort.

Collectively, our study demonstrates the ability to reduce the clinical heterogeneity of MBC into two subgroups with different clinical outcomes, specifically Stage $\mathrm{IV}_{\text {indolent }}$ and Stage $\mathrm{IV}_{\text {aggressive }}$ as a first step to a more individualized approach to treatment selection and more rational drug development. This stratification can then be complemented by molecular analysis of CTCs and cell-free circulating tumor DNA to further advance understanding of molecular drivers and improve treatment selection (Paolillo et al., 2017; Rossi et al., 2018).

In conclusions, we strongly believe that the large data accumulated over the years and the new combined analysis of the large dataset included in this study strongly supports the notion that CTCs enumeration should be used for prognostic stratification of MBC in two defined group of patients identified as Stage $\mathrm{IV}_{\text {indolent }}$ and Stage $\mathrm{IV}_{\text {aggressive. }}$ Therefore, we recommend that this classification being prospective utilized as stratification factor in future prospective clinical trials.

\section{Funding source}

Lynn Sage Cancer Research Foundation.

\section{Conflict of interest}

None reported.

Dr. Cristofanilli reports the following industry relationships: Pfizer, Inc., Novartis, and Merus

\section{Appendix A. Supplementary data}

Supplementary material related to this article can be found, in the online version, at doi:https://doi.org/10.1016/j.critrevonc.2018.12. 004.

\section{References}

Baselga, J., Campone, M., Piccart, M., et al., 2012. Everolimus in postmenopausal hormone-receptor-positive advanced breast cancer. N. Engl. J. Med. 366, 520-529.

Bidard, F.C., Peeters, D.J., Fehm, T., et al., 2014. Clinical validity of circulating tumour cells in patients with metastatic breast cancer: a pooled analysis of individual patient data. Lancet Oncol. 15, 406-414.

Cristofanilli, M., Budd, G.T., Ellis, M.J., et al., 2004. Circulating tumor cells, disease progression, and survival in metastatic breast cancer. N. Engl. J. Med. 351, 781-791.

Cristofanilli, M., Hayes, D.F., Budd, G.T., et al., 2005. Circulating tumor cells: a novel prognostic factor for newly diagnosed metastatic breast cancer. J. Clin. Oncol. 23, 1420-1430.

DeSantis, C.E., Ma, J., Goding Sauer, A., Newman, L.A., Jemal, A., 2017. Breast cancer statistics, 2017, racial disparity in mortality by state. CA Cancer J. Clin. 67, 439-448.

Duffy, M.J., Harbeck, N., Nap, M., et al., 2017. Clinical use of biomarkers in breast cancer: updated guidelines from the European Group on Tumor Markers (EGTM). Eur. J. Cancer 75, 284-298.

Finn, R.S., Crown, J.P., Lang, I., et al., 2015. The cyclin-dependent kinase 4/6 inhibitor palbociclib in combination with letrozole versus letrozole alone as first-line treatment of oestrogen receptor-positive, HER2-negative, advanced breast cancer (PALOMA-1/ TRIO-18): a randomised phase 2 study. Lancet Oncol. 16, 25-35.

Finn, R.S., Martin, M., Rugo, H.S., et al., 2016. Palbociclib and letrozole in advanced breast cancer. N. Engl. J. Med. 375, 1925-1936.

Finn, R.S., Crown, J., Lang, I., et al., 2017. Overall survival results from the randomized phase II study of palbociclib (P) in combination with letrozole (L) vs letrozole alone for frontline treatment of ER + /HER2- advanced breast cancer (PALOMA-1; TRIO18). J. Clin. Oncol. 35 suppl; abstr 1001.

Ghoncheh, M., Pournamdar, Z., Salehiniya, H., 2016. Incidence and mortality and epidemiology of breast cancer in the world. Asian Pac. J. Cancer Prev. 17, 43-46.

Giuliano, A.E., Connolly, J.L., Edge, S.B., et al., 2017. breast cancer-major changes in the american joint committee on cancer eighth edition cancer staging manual. CA Cancer J. Clin. 67, 290-303.

Gradishar, W.J., Anderson, B.O., Balassanian, R., et al., 2018. Breast cancer, version 4.2017, NCCN clinical practice guidelines in oncology. J. Compr. Cancer Netw. 16, 310-320.

Hortobagyi, G.N., Stemmer, S.M., Burris, H.A., et al., 2016. Ribociclib as first-line therapy for HR-Positive, advanced breast cancer. N. Engl. J. Med. 375, 1738-1748.

Koren, S., Bentires-Alj, M., 2015. Breast tumor heterogeneity: source of fitness, hurdle for therapy. Mol. Cell 60, 537-546.

Meng, S., Tripathy, D., Shete, S., et al., 2006. UPAR and HER-2 gene status in individual breast cancer cells from blood and tissues. Proc. Natl. Acad. Sci. U. S. A. 103, 17361-17365.

Paolillo, C., Mu, Z., Rossi, G., et al., 2017. Detection of activating estrogen receptor gene (ESR1) mutations in single circulating tumor cells. Clin. Cancer Res. 23, 6086-6093.

Piccart, M., Hortobagyi, G.N., Campone, M., et al., 2014. Everolimus plus exemestane for hormone-receptor-positive, human epidermal growth factor receptor-2-negative advanced breast cancer: overall survival results from BOLERO-2. Ann. Oncol. 25, 2357-2362.

Polyak, K., 2011. Heterogeneity in breast cancer. J. Clin. Invest. 121, 3786-3788.

Powell, A.A., Talasaz, A.H., Zhang, H., et al., 2012. Single cell profiling of circulating tumor cells: transcriptional heterogeneity and diversity from breast cancer cell lines. PLoS One 7, e33788.

Rossi, G., Mu, Z., Rademaker, A.W., et al., 2018. Cell-free DNA and circulating tumor cells: comprehensive liquid biopsy analysis in advanced breast cancer. Clin. Cancer Res. 24, 560-568.

Siegel, R.L., Miller, K.D., Jemal, A., 2018. Cancer statistics, 2018. CA Cancer J. Clin. (68), $7-30$.

Sledge Jr., G.W., Toi, M., Neven, P., et al., 2017. MONARCH 2: abemaciclib in combination with fulvestrant in women with HR + /HER2- advanced breast cancer who had progressed while receiving endocrine therapy. J. Clin. Oncol. 35, 2875-2884.

Smerage, J.B., Barlow, W.E., Hortobagyi, G.N., et al., 2014. Circulating tumor cells and response to chemotherapy in metastatic breast cancer: SWOG S0500. J. Clin. Oncol. $32,3483-3489$.

Turner, N.C., Ro, J., Andre, F., et al., 2015. Palbociclib in Hormone-Receptor-Positive advanced breast cancer. N. Engl. J. Med. 373, 209-219.

Van Poznak, C., Somerfield, M.R., Bast, R.C., et al., 2015. Use of biomarkers to guide decisions on systemic therapy for women with metastatic breast cancer: american society of clinical oncology clinical practice guideline. J. Clin. Oncol. 33, 2695-2704.

Weigelt, B., Peterse, J.L., van't Veer, L.J., 2005. Breast cancer metastasis: markers and models. Nat. Rev. Cancer 5, 591-602.

Yu, M., Bardia, A., Wittner, B.S., et al., 2013. Circulating breast tumor cells exhibit dynamic changes in epithelial and mesenchymal composition. Science 339, 580-584.

Yu, M., Bardia, A., Aceto, N., et al., 2014. Cancer therapy. Ex vivo culture of circulating breast tumor cells for individualized testing of drug susceptibility. Science 345, 216-220. 